Jurnal ELTIKOM, Vol. 2, No. 2, Desember 2018, hal. 94-101 ISSN 2598-3245 (Print), ISSN 2598-3288 (Online)

Tersedia online di http://eltikom.poliban.ac.id DOI : http://doi.org/10.31961/eltikom.v2i2.83

\title{
PENGEMBANGAN APLIKASI PEMBELAJARAN UNTUK TOPIK HTML5 MENGGUNAKAN MODEL USER-CENTERED DESIGN
}

\author{
Maretha Ruswiansari'), Nanang Fakhrur Rozi ${ }^{2}$ \\ ${ }^{1,2)}$ Institut Teknologi Adhi Tama Surabaya \\ e-mail: maretharuswiansari@gmail.com ${ }^{1)}$, nanang@itats.ac.id ${ }^{2)}$
}

\begin{abstract}
Formal education at the upper secondary level in Indonesia can be divided into two groups, general educa-tion (SMA) and vocational education (SMK). Vocational schools are targeted to be ready to work after gradu-ation while SMA is only given 30\% work skills because the education model is more emphasis on theory. There-fore, many SMA graduates are unemployed or work odd jobs when unable to continue their education to a higher level. This study aims to develop a learning application with the topic of HTML5 so that it can be used by students, especially SMA, in improving their skills in the field of web development. This application was developed using the User-Centered Design model. This model can be used to capture the requirements deeply because they are centered on the user aspect. Therefore, the application will have high usability for the user. Applications are developed as a web application. An automatic assistant in the form of a bot is also embedded in this application. It will provide direct instructions for users who have difficulty in finding the materials. The success criteria of the model implementation are based on the ease of use and usefulness level of the applica-tion. The result shows that the average ease of use level was $84.32 \%$ and the usefulness was $87.5 \%$. In other words, the application can meet the requirements of the users.
\end{abstract}

Keywords: Automatic assistant, HTML5, Learning application, Web, User-Centered Design

\begin{abstract}
ABSTRAK
Pendidikan formal pada jenjang menengah atas di Indonesia dapat dibedakan menjadi dua kelompok, yakni pendidikan uтum (SMA) dan kejuruan (SMK). SMK ditargetkan siap bekerja setelah lulus sedangkan SMA hanya diberikan keterampilan kerja sebesar 30\% karena model pendidikannya memang lebih menekankan pada teori. Sehingga, tidak sedikit lulusan SMA yang menganggur atau bekerja secara serabutan ketika tidak mampu melanjutkan pendidikannya ke jenjang yang lebih tinggi. Penelitian ini bertujuan untuk mengembangkan aplikasi pembelajaran dengan topik HTML5 agar dapat digunakan oleh para siswa, khususnya SMA, dalam meningkatkan keterampilannya di bidang pengembangan web. Aplikasi ini dikembangkan menggunakan model User-Centered Design. Model ini dapat digunakan untuk menangkap kebutuhan secara mendalam karena berpusat pada aspek pengguna. Dengan demikian, aplikasi akan memiliki daya guna yang tinggi bagi pengguna. Aplikasi dikembangkan dalam bentuk aplikasi web. Pada aplikasi ini juga ditanamkan asisten otomatis dalam bentuk bot yang akan memberikan petunjuk secara langsung bagi pengguna yang mengalami kesulitan dalam mencari materi. Keberhasilan penerapan model didasarkan pada faktor ease of use dan usefulness dari aplikasi. Berdasarkan uji coba, didapatkan rata-rata tingkat easy of use sebesar 84,32\% dan usefulness sebesar 87,5\%. Dengan kata lain, aplikasi dapat memenuhi kebutuhan pengguna yang ditargetkan.
\end{abstract}

Kata Kunci: Aplikasi pembelajaran, Asisten otomatis, HTML5, Web, User-Centered Design

\section{Pendahuluan}

I NDONESIA merupakan negara kepulauan dengan jumlah pulau sebanyak 13.466 [1]. Lokasi geografis Indonesia terletak pada $6^{\circ}$ lintang utara sampai dengan $11^{\circ}$ lintang selatan. Luasnya bentangan wilayah Indonesia tersebut berasosiasi langsung dengan jumlah penduduk beserta segala macam permasalahannya. Masalah utama yang dapat dilihat antara lain tingkat kemiskinan yang juga akan berasosiasi dengan tingkat pengangguran penduduknya. Tingkat pengangguran penduduk di Indonesia tetap menjadi pekerjaan rumah yang harus diselesaikan.

Berdasarkan informasi dari [2], tingkat pengangguran terbesar di Indonesia saat ini masih didominasi 
oleh lulusan Sekolah Menengah Kejuruan (SMK) dan Sekolah Menengah Atas (SMA). Meski secara statistik tingkat pengangguran lulusan SMA berada di bawah SMK, namun tingkat pengangguran tersebut tidak mencerminkan seberapa sesuai kemampuan dan bidang yang pernah dipelajari saat sekolah dengan pekerjaan yang tengah dilakukan. Hal tersebut mengingat perbedaan model pendidikan keduanya, SMK disiapkan untuk bekerja setelah lulus dengan bekal kemampuan bidang yang spesifik dan praktis, sementara SMA hanya diberikan keterampilan kerja $30 \%$ karena lebih berfokus pada teori. Keterampilan kerja spesifik di SMA umumnya diberikan dalam bentuk kegiatan ekstra yang terbatas, tidak masuk dalam kurikulum (akademik) sekolah.

Kompetensi kerja yang antara lain menggambarkan keterampilan kerja seseorang merupakan hal yang penting untuk dimiliki agar bisa terjun ke dunia industri. Industri akan sangat membutuhkan sumber daya manusia dengan kompetensi kerja yang mumpuni dan spesifik. Pada akhirnya, sumber daya manusia yang kompeten tersebut akan memberikan dampak positif terhadap kinerja dan perkembangan perusahaan [3]. Bahkan, bukan tidak mungkin kompetensi yang dimiliki tersebut dapat menjadi pemicu berdirinya perusahaan-perusahaan baru.

Untuk mendukung hal tersebut, dibutuhkan pemahaman dan penguasaan atas keterampilanketerampilan tertentu. Dengan perkembangan arah bisnis kreatif yang semakin meningkat [4] serta teknologi yang terus bergerak cepat, pembelajaran secara formal akan sangat tidak mencukupi. Dibutuhkan sumber-sumber belajar lain yang mampu mendukung tercapainya kompetensi kerja tersebut. Salah satu sumber belajar yang dapat dimanfaatkan saat ini antara lain aplikasi pembelajaran.

Beberapa aplikasi pembelajaran yang sudah dikembangkan antara lain [5] yang mengembangkan teknologi augmented reality untuk menunjang pemahaman siswa SMK dalam memahami materi yang disampaikan menggunakan pendekatan ilmiah (scientific approach), materi-materi yang umumnya bersifat abstrak. Hasilnya, pemanfaatan aplikasi dapat membantu siswa untuk memenuhi kebutuhan peningkatan keterampilannya, termasuk sisi kognitif dan afektifnya. Pemanfaatan aplikasi juga dilakukan oleh [6] untuk meningkatkan prestasi belajar siswa kelas XI program keahlian Teknik Kendaraan Ringan di SMK Muhammadiyah 3 Yogyakarta tahun pelajaran 2012/2013. Hasilnya, pemanfaatan aplikasi tersebut dapat memberikan kontribusi positif atas prestasi belajar pada salah satu materi yang diteliti.

Dalam mengembangkan aplikasi pembelajaran, berbagai model pengembangan dapat digunakan. Model atau pendekatan yang pernah digunakan oleh peneliti terdahulu antara lain [7] yang menggunakan ADDIE (analysis, design, development, implementation, and evaluation) untuk mengembangkan aplikasi pembelajaran dengan topik TIK (Teknologi Informasi dan Komunikasi). Model ini merupakan model yang umum digunakan dalam pengembangan aplikasi. Hasilnya, aplikasi memiliki tingkat penerimaan rata-rata sebesar 88,9\%. Peneliti lain menggunakan UCD (User-Centered Design) dalam mengembangkan aplikasi seluler untuk mendukung pembelajaran mata kuliah English Intensive Course di Jurusan Pendidikan Bahasa Inggris Universitas Negeri Gorontalo [8]. Pendekatan ini berfokus pada pengguna sebagai tujuan utama. Terdapat empat tahapan pada model UCD, yaitu identifikasi sasaran pengguna, analisis kebutuhan, desain sistem, dan evaluasi sistem [9]. Hasilnya, aplikasi dinyatakan sangat membantu mahasiswa dalam menguasai materi kuliah. Selain itu, pemanfaatan UCD membuat mahasiswa sangat tertarik untuk menggunakan aplikasi yang dikembangkan.

Mengingat efektivitas pemanfaatan aplikasi tersebut dalam proses pembelajaran, maka penelitian ini mencoba untuk mengembangkan aplikasi pembelajaran yang serupa dengan topik HTML5 yang utamanya menarget ke siswa-siswa SMA. Target tersebut diambil dengan melihat jumlah siswa SMA yang lebih banyak dibandingkan dengan SMK [10], [11] sehingga memiliki potensi lebih besar untuk mengisi posisi-posisi pekerjaan yang ada. Aplikasi akan dikembangkan dengan memanfaatkan model UCD serta menanamkan fitur asisten otomatis guna meningkatkan ketertarikan siswa dalam belajar sehingga kompetensi yang diharapkan akan tercapai.

\section{A. Rekayasa Perangkat Lunak}

\section{TINJAUAN PUSTAKA}

Rekayasa perangkat lunak merupakan sebuah pengaplikasian teknik, pendekatan sistematis dan saintifik untuk proses pengembangan, pengoperasian, dan perawatan perangkat lunak dengan tujuan dasar menciptakan sebuah perangkat lunak yang efisien dengan harga yang rendah [12]. Rekayasa perangkat lunak berfokus pada pengembangan subrutin atau blok kode program. Subrutin tersebut 
mempunyai unjuk kerja tertentu dan dapat digunakan sewaktu-waktu sesuai dengan kebutuhan [13]. Saat perangkat lunak dikembangkan, banyak sekali dokumen-dokumen yang dikumpulkan dan dihasilkan, mulai dari dokumen kebutuhan, use case, dokumen desain, rencana pengetesan, materimateri, rangkuman-rangkuman sehubungan dengan proyek, dan lain-lain. Untuk mendapatkan hasil yang maksimal, pelaksanaan rekayasa kebutuhan yang baik akan dapat membantu pengerjaan proyek perangkat lunak. Pekerjaan ini sangatlah susah dan penting karena rekayasa kebutuhan ini akan menjadi baik-buruknya sebuah aplikasi yang dibangun [14].

Terdapat tiga tujuan utama dari rekayasa perangkat lunak, yaitu mengurangi kompleksitas sistem melalui peningkatan teknik-teknik penalaran, struktur sistem, dan analisis. Pengembangan perangkat lunak yang sederhana memerlukan biaya yang kecil dan lebih mudah diprediksi jika dibandingkan dengan perangkat lunak yang kompleks [15]. Proses-proses rekayasa perangkat lunak merupakan tugastugas yang saling berhubungan satu dengan lainnya melalui daur hidup rekayasa perangkat lunak untuk menerjemahkan kebutuhan pengguna, kebutuhan aplikasi, dan hal-hal yang membatasi rekayasa perangkat lunak untuk dimasukkan dalam sebuah sistem yang memiliki solusi [16].

\section{B. User-Centered Design}

User-Centered Design (UCD) merupakan salah satu pendekatan dalam pengembangan perangkat lunak atau aplikasi yang berbasiskan pengguna. Pendekatan ini tidak hanya berfokus pada pemahaman pengguna pada aplikasi yang dibangun tetapi juga pada pengambilan kebutuhan pengguna yang berpengaruh pada aplikasi yang dibangun [9].

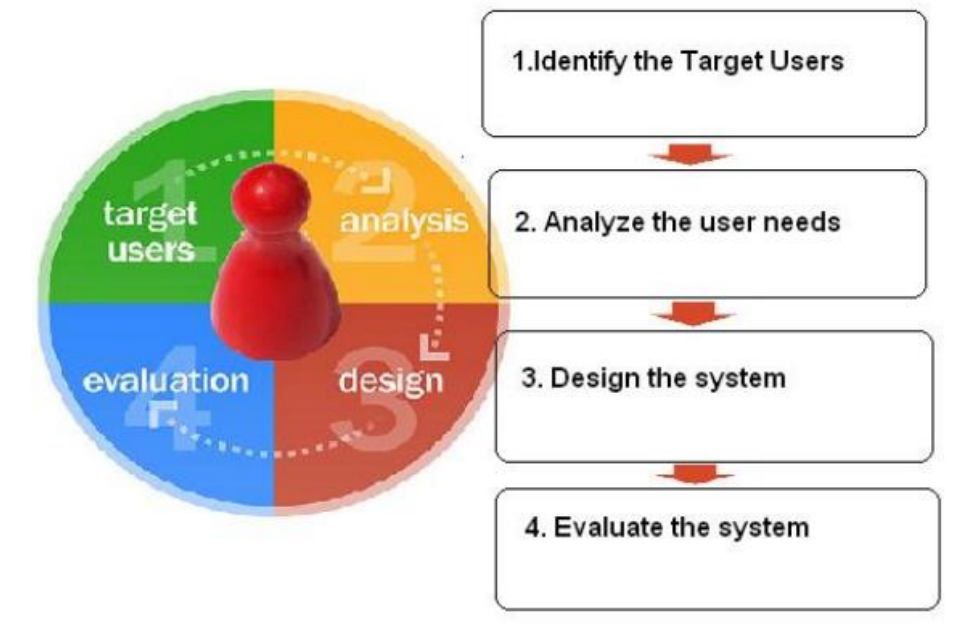

Gambar 1. Pendekatan User-Centered Design pada proses pengembangan aplikasi [9]

Pada Gambar, dapat dilihat bahwa ada empat kegiatan pada pendekatan UCD, yaitu identifikasi sasaran pengguna, analisis kebutuhan pengguna, desain sistem, dan evaluasi sistem. Identifikasi sasaran pengguna merupakan proses penentuan pengguna aplikasi yang akan disasar atau ditargetkan; Analisis kebutuhan pengguna merupakan proses penentuan kebutuhan-kebutuhan yang diperlukan oleh pengguna sehubungan dengan materi yang ada; Desain sistem merupakan kegiatan pembuatan sistem yang dibutuhkan untuk pengembangan produk, dalam hal ini aplikasi; Evaluasi sistem merupakan kegiatan yang berfungsi untuk pengevaluasian, pengurangan, ataupun penambahan terhadap sistem yang telah dikembangkan apabila diperlukan.

\section{HTML5}

HTML5 (HyperText Markup Language versi 5) yang merupakan salah satu standar dalam mengembangkan situs web berkaitan erat dengan potensi pekerjaan yang cukup besar. Web antara lain dapat digunakan untuk mempromosikan produk atau bisnis. Berdasarkan data statistik dalam [4], hingga 2016, web merupakan jalur promosi kedua tertinggi setelah media sosial $(28,25 \%)$ yang digunakan oleh para pelaku usaha kreatif.

Sebuah situs web biasanya dapat diakses melalui peramban (browser), misalnya Google Chrome, Firefox, Microsoft Edge, Opera, Safari, dan lainnya. Situs web secara fisik dikatakan sebagai kumpulan dokumen HTML yang dibuat dengan menggunakan tag-tag HTML [17]. HTML5 merupakan pengembangan dari HTML versi sebelumnya dengan beberapa penambahan atau perubahan. HTML5 
dapat menjadikan sebuah laman web lebih hidup, pintar, cepat, dan aman [18]. Contoh dokumen HTML dapat dilihat pada Gambar.

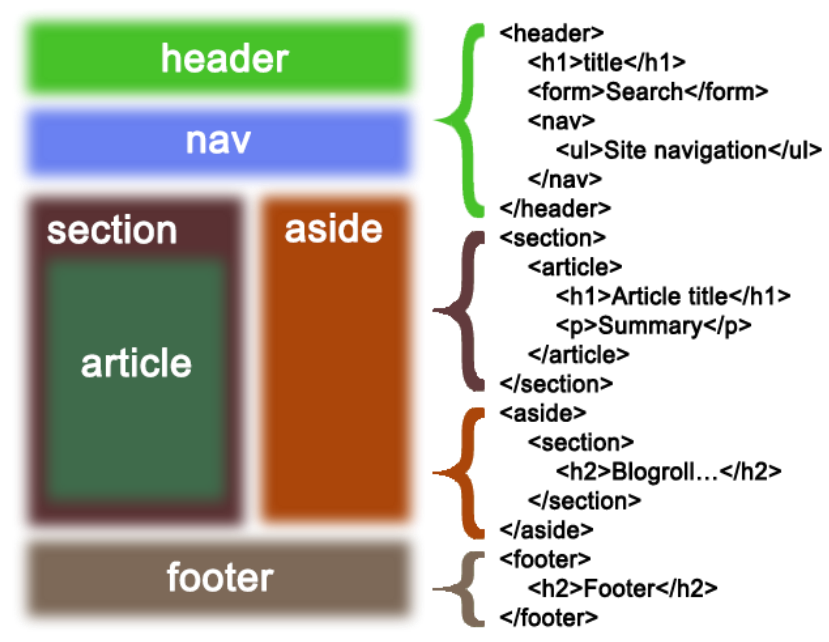

Gambar 2. Struktur HTML5 pada pengembangan web [19]

Bagian kiri Gambar merupakan ilustrasi hasil penampilan dokumen HTML pada peramban sedangkan bagian kanan merupakan bentuk fisik dokumen yang berisi tag-tag HTML. Bagian header berisi identitas situs web yang umumnya diletakkan di bagian atas. Bagian nav digunakan untuk mendefinisikan fungsi navigasi. Bagian section merupakan bagian umum, antara lain untuk mengelompokkan subbagian laman web. Bagian article merupakan bagian untuk meletakkan artikel atau berita. Bagian aside merupakan bagian konten laman web yang umumnya diletakkan pada bagian kiri atau kanan (sidebar). Bagian footer, merupakan bagian yang berisi informasi pencipta, informasi hak cipta, atau lainnya.

HTML5 berisi banyak pengembangan atau perbaikan HTML versi sebelumnya, mulai dari elemen

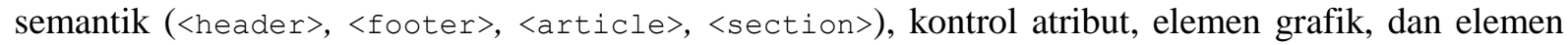
multimedia (<audio>, <video>). Bahkan, terdapat hal baru pada HTML5 yaitu API (Application Progamming Interface), antara lain: geolocation, drag and drop, local storage, application cache, web worker, dan SSE.

\section{Metode Penelitian}

Penelitian ini menggunakan pendekatan User-Centered Design dalam mengembangkan aplikasi. User-Centered Design digunakan saat proses rekayasa kebutuhan dari pengembangan aplikasi. Kegiatan pengembangan aplikasi terdiri atas beberapa bagian: studi literatur, rekayasa kebutuhan (requirement analysis), pembuatan program (code), pengetesan (test), dan implementasi (implementation) seperti tampak pada Gambar .

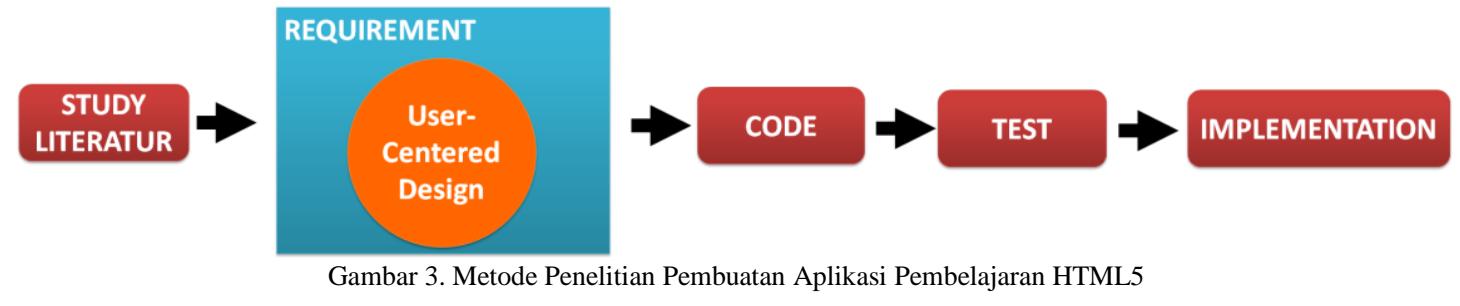

Pada Gambar, studi literatur dilakukan dengan membaca berita yang ada di media digital terkait isu-isu yang sedang berkembang serta model atau metode-metode yang dapat digunakan dalam pengembangan aplikasi. Tahap rekayasa kebutuhan dilakukan untuk mendapatkan kebutuhan-kebutuhan sehubungan dengan pengembangan aplikasi. Untuk melakukan rekayasa kebutuhan, digunakan pendekatan UserCentered Design. Tahap pembuatan program dilakukan setelah kebutuhan telah terkumpul. Pengujian dilakukan dengan mengacu pada penghitungan faktor ease of use dan usefulness atas aplikasi yang telah dikembangkan. Pengujian ini dilakukan dengan melakukan survei kepada target pengguna, dalam hal ini SMA-SMA di kota Surabaya. Lima pertanyaan akan diajukan berkaitan dengan faktor ease of use 
dan dua pertanyaan terkait faktor usefulness seperti terlihat pada Tabel II. Kegiatan implementasi dilakukan dengan cara mengunggah aplikasi ke server yang telah dipilih agar siap diakses oleh khalayak umum.

TABEL II

PERTANYAAN SURVEI UNTUK FAKTOR EASE OF USE DAN USEFULNESS

\begin{tabular}{ll}
\hline \hline No. & Pertanyaan \\
\hline Faktor & Ease of Use \\
\hline Q1 & Kemudahan penggunaan aplikasi \\
Q2 & Kemudahan pengaksesan menu-menu pada aplikasi \\
Q3 & Kemudahan pengaksesan aplikasi secara online \\
Q4 & Kemudahan proses login \\
Q5 & Kemudahan pengaksesan materi \\
\hline Faktor & Usefulness \\
Q6 & Kebergunaan aplikasi bagi diri sendiri \\
Q7 & Kebergunaan aplikasi bagi masyarakat/orang lain \\
\hline \hline
\end{tabular}

\section{HASIL DAN PEMBAHASAN}

Berdasarkan kegiatan studi literatur, didapatkan informasi antara lain:

1) kalangan SMA tidak memiliki materi tentang pendidikan ataupun ilmu yang berhubungan dengan teknologi informasi dan komunikasi pada konteks pemrograman;

2) banyak berkembang perusahaan rintisan (startup) pada bidang teknologi informasi di Indonesia, terutama di Surabaya. Pengembang perusahaan rintisan tersebut umumnya merupakan kalangan muda dengan usia 19-30 tahun yang antara lain terdiri atas sumber daya dengan kemampuan pemrograman;

3) banyaknya lomba pengembangan aplikasi. Berdasarkan pengamatan, ternyata tidak banyak aplikasi yang memberikan bantuan belajar secara daring (online) khususnya bagi siswa-siswa SMA.

Memasuki tahap analisis kebutuhan, yang sekaligus memanfaatkan model User-Centered Design, terdapat empat langkah utama yang dilakukan sebagaimana ilustrasi pada Gambar . Langkah pertama yakni identifikasi target pengguna. Langkah ini didasarkan pada hasil studi literatur yang telah dilakukan. Peneliti menentukan fokus (target) pengguna pada siswa SMA. Langkah kedua adalah analisis kebutuhan pengguna. Pada langkah ini, survei dilakukan kepada dua SMA yang ada di Surabaya, yaitu SMA-X dan SMA-Y. Berdasarkan hasil survei terhadap siswa dan guru, didapatkan kebutuhan pengguna sebagaimana tampak pada Tabel III.

TABEL III

KEBUTUHAN Siswa DAN GURU PADA MATERI PEMBELAJARAN HTML5

\begin{tabular}{cll}
\hline \hline No. & Siswa SMA & Pemateri (Guru) \\
\hline 1 & Browsing materi & Membuat materi pembelajaran \\
2 & Menjadi anggota atau member & Membuat video pembelajaran \\
3 & Mengakses materi pembelajaran & Membuat soal pembelajaran \\
4 & Mengakses video pembelajaran & Mendapatkan sertifikat pemateri \\
5 & Mengakses soal-soal pembelajaran & Mendapatkan info subscriptor \\
6 & Mendapatkan sertifikat pembelajaran & Mendapatkan info jumlah pengakses materi \\
7 & & Mendapatkan info penyelesaian materi \\
\hline \hline
\end{tabular}

Dapat dilihat pada Tabel III, kebutuhan yang diperoleh terkait fitur aplikasi yang akan dikembangkan antara lain terdiri atas 6 poin yang berasal dari siswa dan 7 poin dari guru. Selain survei berkaitan dengan konsep aplikasi, dilakukan pula survei spesifik tentang HTML5 dengan daftar pertanyaan seperti tampak pada Tabel IV.

TABEL IV

SURVEI MATERI HTML5 PADA SISWA SMA

\begin{tabular}{ll}
\hline \hline No. & Pertanyaan \\
\hline M1 & Apakah Anda mendapatkan pengetahuan khusus (ekstrakurikuler) untuk pemrograman HTML5 di sekolah? \\
M2 & Apakah Anda pernah mendengar pemrograman HTML5? \\
M3 & Apakah Anda memiliki komputer/laptop? \\
M4 & Apakah Anda memiliki smartphone? \\
M5 & Apakah Anda menggunakan koneksi internet? \\
M6 & Jika ya, media koneksi internet apa yang Anda gunakan (smartphone/modem/Wi-Fi)? [merujuk ke pertanyaan no. 5] \\
M7 & Apakah Anda pernah menggunakan smartphone untuk mendapatkan informasi tugas/belajar bagi keperluan sekolah? \\
M8 & Apakah Anda bisa membuat program dengan menggunakan HTML5? \\
M9 & Jika terdapat media pembelajaran HTML5 dalam bahasa Indonesia, apakah Anda berminat untuk menggunakan media tersebut \\
& untuk belajar pemrograman HTML5? \\
\hline \hline
\end{tabular}

Hasil survei menggunakan pertanyaan-pertanyaan pada Tabel IV dapat dilihat pada Tabel V. 
TABEL V

HASIL SURVEI MATERI HTML5 PADA SiSWa SMA

\begin{tabular}{ll}
\hline \hline No. Pertanyaan & Simpulan Jawaban Siswa atas Pertanyaan \\
\hline M1 & $100 \%$ tidak ada kegiatan ekstrakurikuler pemrograman HTML5 di sekolah \\
M2 & $95 \%$ pernah mendengar tentang pemrograman HTML5 \\
M3 & $95 \%$ memiliki komputer/laptop \\
M4 & $100 \%$ memilliki smartphone \\
M5 & $100 \%$ menggunakan koneksi internet \\
M6 & $65 \%$ menggunakan smartphone, $30 \%$ menggunakan Wi-Fi, dan 5\% menggunakan modem \\
M7 & $100 \%$ pernah menggunakan smartphone untuk menyelesaikan tugas atau belajar terkait keperluan sekolah \\
M8 & $90 \%$ tidak dapat membuat program dengan HTML5 dan 10\% dapat membuat program dengan HTML5 \\
M9 & $75 \%$ berminat untuk menggunakan media pembelajaran HTML5 dan 25\% tidak berminat \\
\hline \hline
\end{tabular}

Berdasarkan hasil analisis kebutuhan yang telah dilakukan, langkah UCD ketiga yang dilakukan yakni mendesain rancangan aplikasi pembelajaran HTML5. Hasil perancangan tersebut dapat dilihat pada Gambar .

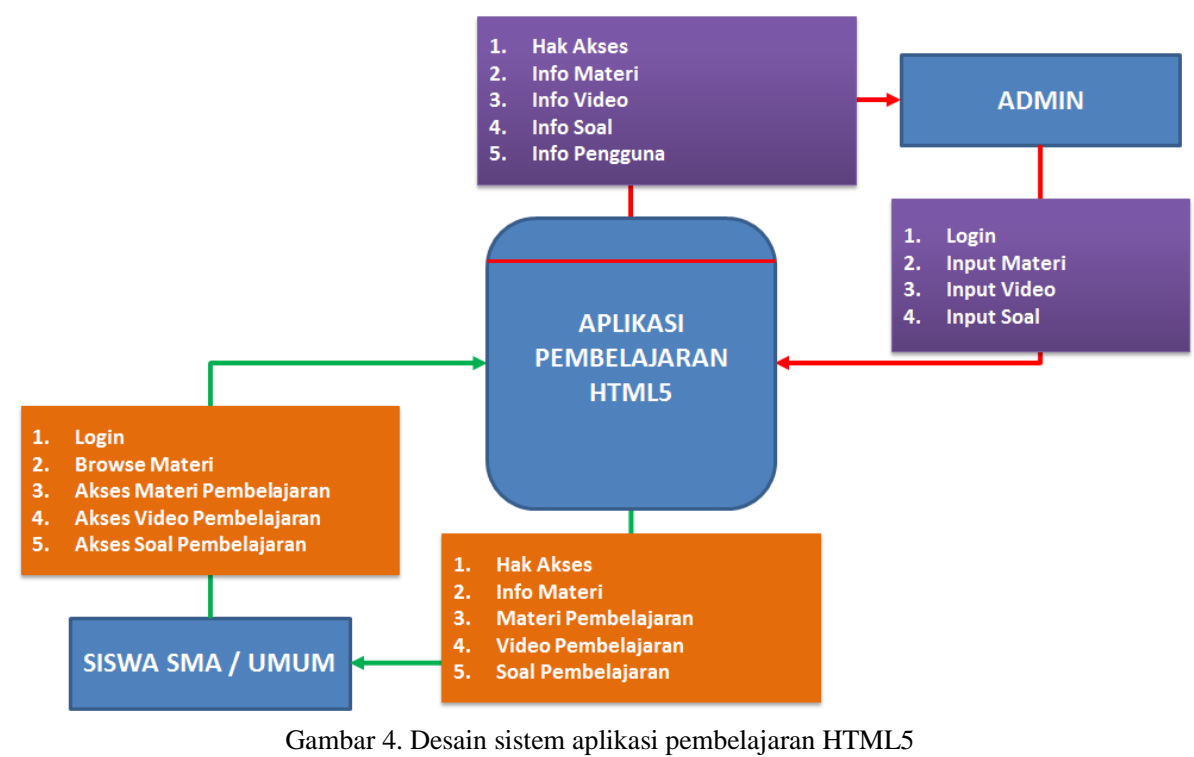

Dari Gambar, dapat dilihat bahwa pengguna utama aplikasi adalah siswa SMA. Pengguna lainnya yakni Admin yang bertanggung jawab memasukkan materi pembelajaran. Siswa harus melakukan pendaftaran sebagai anggota untuk dapat mengakses materi yang ada. Pada materi pembelajaran yang ada, disediakan soal-soal latihan yang dapat digunakan untuk meningkatkan kemampuan siswa. Materi dibedakan ke dalam tiga level: easy (mudah), medium (menengah), dan hard (sulit). Pembagian tersebut digunakan agar pengguna dapat memilih level materi sesuai dengan kemampuan yang telah dikuasai. Untuk memudahkan dan meningkatkan minat siswa terhadap aplikasi, ditambahkan pula fasilitas asisten otomatis berbasis bot yang dapat digunakan untuk menemukan materi dengan cepat.

Langkah keempat UCD adalah evaluasi sistem yang terintegrasi dengan kegiatan pengujian aplikasi. Sebelum langkah tersebut dilakukan, aplikasi dibuat pada kegiatan pembuatan program. Aplikasi dibuat dalam bentuk aplikasi web responsif dengan sehingga memungkinkan untuk dapat diakses melalui smartphone. Tagline aplikasinya yaitu Tingkatkan Kompetensi Membuat Websitemu di Belajar Kompeten. Asisten otomatis (Phiphin) juga ditanamkan ke dalam aplikasi. Hasil pembuatan program dapat dilihat pada Gambar dan Gambar. Dapat dilihat pada Gambar bahwa asisten otomatis akan langsung menyapa pengguna seperti seorang manusia yang sedang berinteraksi. Pengguna selanjutnya dapat mengakses materi yang disarankan oleh asisten otomatis melalui tautan yang disediakan. Sedangkan Gambar menjelaskan tentang gambaran pembagian level materi yang bisa diakses oleh pengguna.

Evaluasi terhadap aplikasi pada akhirnya dilakukan. Terdapat 112 pengguna yang telah mencoba aplikasi yang dikembangkan. Dari 112 pengguna tersebut, terdapat 10 guru dan 102 siswa SMA. Setelah menggunakan aplikasi tersebut, peneliti memberikan pertanyaan kepada pengguna berdasarkan pertanyaan yang telah disebutkan pada Tabel II. 


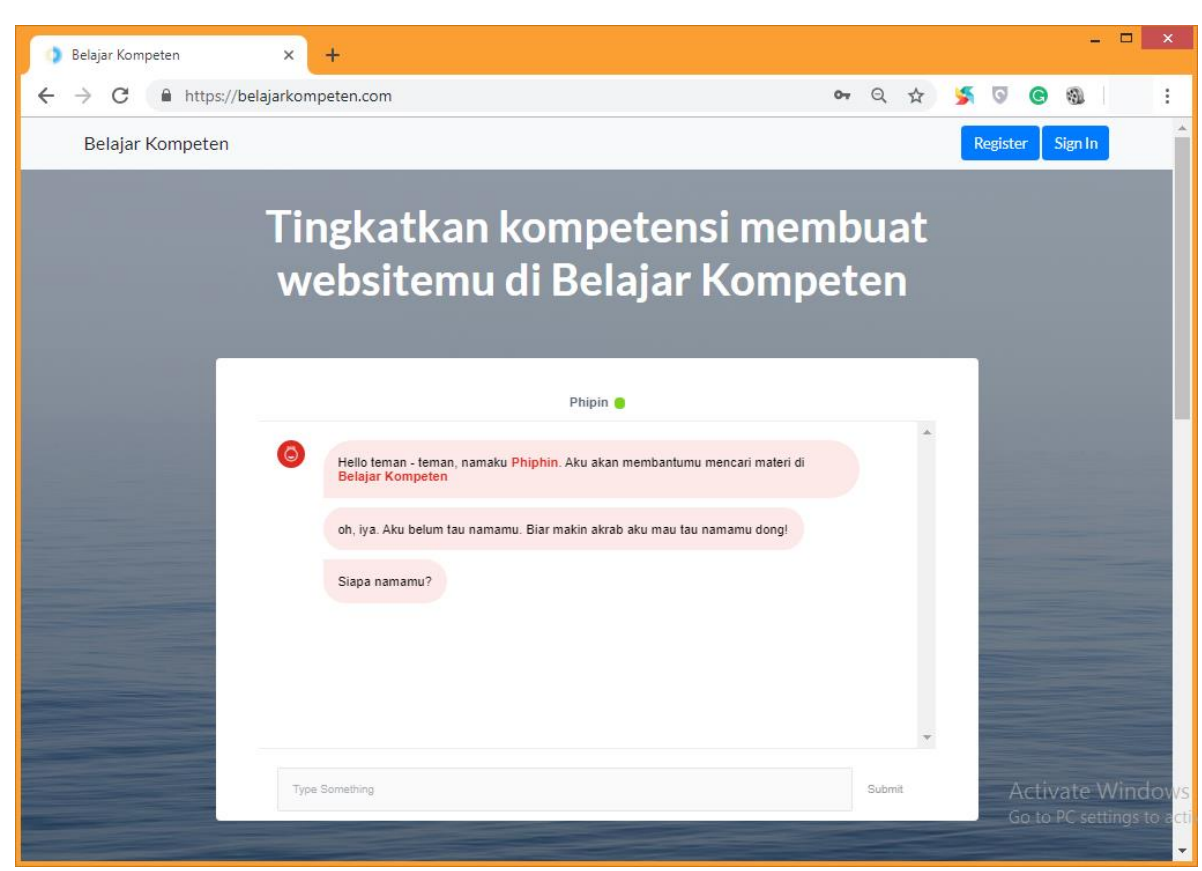

Gambar 5. Halaman utama aplikasi

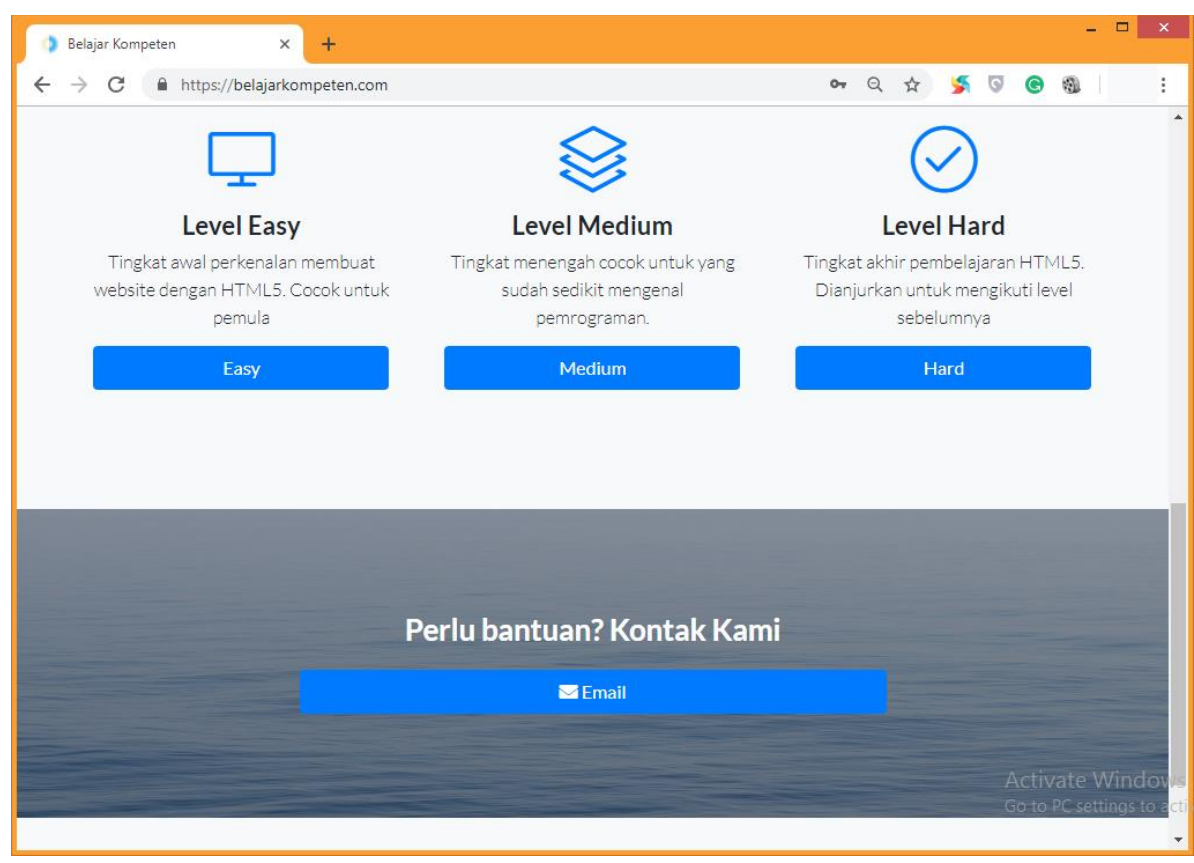

Gambar 6. Tingkat kesulitan pembelajaran HTML5 pada aplikasi

Berdasarkan jawaban pengguna, didapatkan bahwa untuk Q1 (pertanyaan ke-1), nilai yang didapatkan yaitu $88,75 \%$ yang artinya aplikasi mudah untuk digunakan. Untuk Q2, nilai yang didapatkan yaitu $88,04 \%$. Untuk Q3, nilai yang didapatkan yaitu $72,32 \%$. Untuk Q4, nilai yang didapatkan yaitu $85,89 \%$. Sedangkan Q5 mendapatkan nilai 86,61\%. Apabila dirata-rata, nilainya adalah 84,32\% yang berarti aplikasi sangat mudah digunakan (faktor ease of use). Untuk dampak bagi masyarakat ataupun pribadi, dengan adanya aplikasi, berdasarkan faktor usefulness, untuk Q6 nilai yang dihasilkan sebesar 89,64\% dan Q7 sebesar 85,36\%. Rata-ratanya adalah $87,5 \%$ yang berarti materi pada aplikasi sangat berguna.

Berdasarkan hasil pengujian, didapatkan bahwa aplikasi diterima dan layak digunakan. Hal tersebut sejalan pula dengan penelitian [8] yang telah berhasil mengembangkan aplikasi pembelajaran dengan memanfaakan model UCD. Dengan demikian, kegiatan implementasi dapat dilakukan. Aplikasi kemudian diunggah ke server dengan alamat https://belajarkompeten.com. Sehingga, pengguna dapat mengakses aplikasi tersebut dengan mudah hanya dengan masuk ke alamat tersebut, baik melalui komputer, laptop, ataupun smartphone. 


\section{KESIMPULAN}

Pada penelitian ini, dilakukan pengembangan aplikasi pembelajaran dengan topik HTML5 untuk menjadi salah satu alternatif media belajar guna meningkatkan kemampuan, terutama siswa SMA, dalam menguasai kemampuan pemrograman HTML5. Model pengembangan aplikasi yang digunakan yakni User-Centered Design (UCD) berdasarkan keberhasilan yang juga dilakukan oleh penelitian terdahulu. Nilai rata-rata faktor ease of use dan usefulness aplikasi masing-masing adalah $84,32 \%$ dan $87,5 \%$ yang berarti aplikasi layak untuk digunakan dan memiliki tingkat kebergunaan yang tinggi untuk masyarakat, khususnya pengguna yang disasar.

\section{UCAPAN TERIMA KASIH}

Terima kasih diucapkan kepada Kementerian Riset, Teknologi, dan Pendidikan Tinggi yang telah mendukung penelitian ini dalam bentuk hibah Penelitian Dosen Pemula (PDP) tahun anggaran 2017.

\section{DAFTAR PUSTAKA}

[1] L. D. Larasati, “Tantangan Internal dalam Mewujudkan Indonesia Sebagai Poros Maritim Dunia,” Jurnal Hubungan Internasional, vol. 2, hlm. 99-116, Des 2017.

[2] JawaPos.com, “Tingkat Pengangguran Lulusan SMA dan SMK Paling Besar," 2018. [Daring]. Tersedia pada: https://www.jawapos.com/ekonomi/05/11/2018/tingkat-pengangguran-lulusan-sma-dan-smk-paling-besar. [Diakses: 17-Des-2018].

[3] S. Diah, "Pengaruh Kompetensi Kerja terhadap Kinerja Karyawan Di Kantor PT. Kitadin Tenggarong Seberang," eJournal Administrasi Negara, vol. 5, no. 2, 2017.

[4] Badan Ekonomi Kreatif, "Data Statistik dan Hasil Survei Ekonomi Kreatif," Direktorat Riset dan Pengembangan Ekonomi Kreatif, Deputi Riset Edukasi dan Pengembangan, Badan Ekonomi Kreatif, Jakarta, 2017.

[5] M. Mantasia dan H. Jaya, "Pengembangan Teknologi Augmented Reality Sebagai Penguatan dan Penunjang Metode Pembelajaran di SMK untuk Implementasi Kurikulum 2013,” Jurnal Pendidikan Vokasi, vol. 6, no. 3, hlm. 281-291, Nov 2016.

[6] A. Kristanto dan P. Roniwijaya, "Kontribusi Pembelajaran Menggunakan Media Berbasis Komputer dan Motivasi Belajar Terhadap Prestasi Belajar Mata Diklat Perawatan Chasis dan Pemindah Tenaga Siswa Kelas XI Program Keaglian Teknik Kendaraan Ringan SMK Muhammadiyah 3 Yogyakarta Tahun Pelajaran 2012/2013," TAMAN VOKASI, vol. 1, no. 1, Mar 2017.

[7] R. Arief, M. I. Wazirudin, A. Rachman, dan D. P. Hapsari, "Pengembangan Aplikasi Pembelajaran TIK Berbasis Web Menggunakan Model ADDIE untuk Siswa SMK," Prosiding Seminar Nasional Sains dan Teknologi Terapan, vol. 6, no. 1, hlm. 509-514, Sep 2018.

[8] M. Rohandi, N. Husain, dan I. W. Bay, "Pengembangan Mobile-Assisted Language Learning Menggunakan User Centered Design," Jurnal Nasional Teknik Elektro dan Teknologi Informasi (JNTETI), vol. 7, no. 1, 2018.

[9] V. Sripathi dan V. Sandru, "Effective Usability Testing - Knowledge of User Centered Design is Key Requirement," International Journal of Emerging Technology and Advanced Engineering, vol. 3, no. 1, 2013.

[10] bps.go.id, "Jumlah sekolah, guru dan murid sekolah menengah atas," Apr-2016. [Daring]. Tersedia pada: https://www.bps.go.id/linkTabelStatis/view/id/1837.

[11] S. N. Puspitasari, "Jumlah SMK Akan Mendominasi," 27-Sep-2015. [Daring]. Tersedia pada: http://www.pikiran-rakyat.com/pendidikan/2015/09/27/343941/jumlah-smk-akan-mendominasi.

[12] D. Harminder Pal Singh, "Improving Software Reliability, Productivity and Quality Using Software Metrics," International Journal of Computer Science and Technology, vol. 7, no. 4, hlm. 16-19, Des 2016.

[13] J. Kaur, "A Retrospection of Software Component Selection Techniques Using Computational Intelligence," IJLTET, vol. 6, no. 4, hlm. 489-495, Mar 2016.

[14] R. Stephens, Beginning Sofware Engineering. Wrox, 2015.

[15] Computer Science Engineering, "Software Engineering," 2016.

[16] M. Biswa Ranjan dan P. Jaya Krushna, "A Study on the Strategic Risk Management in Software Engineering Projects," International Journal of Advance Research in Computer Science and Management Studies, vol. 4, no. 2, hlm. 30-34, Feb 2016.

[17] R. Pulakesh dan R. Dibyendu, "Development of Online Shopping System using ASP.NET Technology and Microsoft SQL," IJARCSMS, vol. 4, no. 4, hlm. 60-68, Apr 2016.

[18] M. West, HTML5 Foundations. Wiley, 2012.

[19] H. C. HTML Career, "HTML5 Structure Document," 2015. [Daring]. Tersedia pada: http://htmlweblearn.blogspot.com/2015/02/html5-structure-document.html. [Diakses: 20-Nov-2018]. 